\title{
THEORY
}

\section{Unspoken Criticality: Developing Scholarly Voices for Minoritized Students through UREs}

Susan G. Mendoza, Grand Valley State University

Dave A. Louis, Texas Tech University

\begin{abstract}
The authors reflect on their work in designing, executing, and evaluating undergraduate research experiences (UREs) that serve students of color, first-generation students, and low-income students. They assert that additional support is needed to prepare students as their cultures and identities intersect with their disciplinary learning and the historical context of the academy. The authors discuss the meaning of scholarly voice, the influence of minoritized cultures on that voice, the integration of their scholarly voice within the discipline, elements of programmatic design that intentionally create space, and experiences that promote a reflective scholarly journey for students. By infusing these elements into the faculty repertoire when mentoring students in UREs and into the framework and culture of UREs, students will be able to actively engage in graduate education from a place of integration and resiliency.
\end{abstract}

Keywords: mentorship, retention, scholarly voice, undergraduate research, underrepresented students

\section{doi: 10.18833/spur/1/4/7}

As colleges and universities continue to explore the potential of undergraduate research experiences (UREs) as effective practice and pedagogy, researchers have studied the benefits of UREs and developed evidence-based best practices (Hunter, Laursen, and Seymour 2007; Hunter et al. 2009; Lopatto 2007). The use of UREs as a vehicle to provide equity in higher education has become mainstream and standard practice (Eagan et al. 2013). Colleges and universities, as well as federal funding agencies, view UREs as an effective way to diversify the pool of students matriculating to graduate school and increase the country's capacity for research and innovation. UREs are essential in this process, as they catalyze students' interest in graduate school (Russell, Hancock, and McCullough 2007) and develop a pipeline through effective mentoring and social support (Phelps-Ward and DeAngelo 2016). Furthermore, research demonstrates that faculty mentorship and acclimation to the discipline is critical to the academic success of students of color, first-generation, and low-income students (DeAngelo, Mason, and Winters 2016; Gittens 2014). This disciplinary socialization creates a sense of connectivity and belonging that positively influences the students' experience and further develops their "competence, self-confidence, social and academic connectedness, and academic identity" (Gittens 2014, 368). As such, this symbiotic interaction between the faculty and students must be examined, understood, and utilized to nurture and support minoritized students. The authors explore these elements as an approach to deepen their practice, as program directors and faculty mentors, and create space for minoritized students that increases their strength of voice, resilience, and integration as scholars.

\section{Addressing Criticality, the Faculty Mentor, and the Underrepresented Student}

When addressing the multifaceted nature and multiple schools of criticality, Brookfield (2005, 14-15) alludes to the idea of "using different forms of reasoning ... the intent of which is to improve skills of analysis and argument disconnected from any particular ideological critique." He continues by noting that criticality "emphasizes the way people learn how to construct, and deconstruct, their own experiences and meanings" (Brookfield 2000, 2 ). Thus, the purpose of this article is to utilize the lived experiences and observations of faculty members engaged 
in UREs to explore the tacit and nuanced exercises that help minoritized students develop a scholarly voice while they are engaged and mentored in undergraduate research.

A critical exploration of faculty members' interactions with students is imperative to improving this researcherbased mentoring dyad. These interactions are the core of any URE; it is through this activity that students become better learners, advance in their scholarly stations, and acquire valuable knowledge about their chosen fields. Tinto (1993) states that student-faculty interactions outside of the classroom result in positive learning and personal growth outcomes for the students. Pascarella and Terenzini (2005) confirm that regular student-faculty interactions directly correlate with better academic performance by students. Therefore, UREs provide the perfect crucible for these interactions. If programs target underrepresented populations for participation, there will undoubtedly be an increase in their engagement on campus. Abdul-Alim (2014) notes that colleges and universities should advise and support underrepresented students to a deeper level. He states that the primary purpose of these faculty-student interactions is to empower students through apprenticeships that build their social capital on campus and assist them in mastering "unwritten, often unspoken norms, values, expectations, behaviors, codes of conduct" (para. 6). For underrepresented students, these may be the elements that ungird a positive undergraduate student experience.

Minoritized and underrepresented students face significant challenges when navigating the culture and structure of college campuses. Despite the diversity within these populations, underrepresented students are defined by their ethnicity, gender/gender identity, socioeconomic status, sexual orientation, and first-generation status, all of which lend to common experiences. These groups experience invalidation, stereotypes, invisibility, lack of connectedness, hostility, and microaggressions (Allen 2016; Museus, Sarinana, and Ryan 2015; Seltzer and Johnson 2009; Strayhorn 2014). Therefore, finding spaces where underrepresented students are understood, are validated, and can engage in a positive and productive endeavor is critical. Castillo and Estudillo (2015) posit that, for minoritized populations, UREs assist in fostering a more amiable campus environment and improving the overall undergraduate experience, increasing interest in graduate education and graduation outcomes, and influencing the career trajectories of these students. UREs are essential to these students, many of whom are marginalized, and act as a catalyst for the development of their scholarly abilities, persona, character, and voice.

\section{Balancing Traditional Measures with Minoritized Scholars' Voices}

In nationally recognized programs, such as the McNair Scholars Program, success is defined quantitatively.
Although many programs utilize qualitative measures to inform program design and refinement, the U.S. Department of Education measures a program's success by the percentage of students who complete an undergraduate research experience, matriculate at a graduate school and are retained after the first year, and attain a $\mathrm{PhD}$. As the Department of Education is the external funding agency, this approach to measuring success is common across programs (Gittens 2014). Quantitative measures such as these leave little room to understand student experience and contextual elements that impact student success.

In reflecting on their experiences designing, executing, and evaluating UREs that serve minoritized students, the authors noted that, although UREs prepare students to understand and fit the model of graduate education, little has been written about approaches that intentionally develop a student's critical scholarly voice in a way that integrates disciplinary and academic identity with cultural identity and knowledge.

\section{Finding a Place in Academic Research}

In her research about faculty mentoring undergraduate research in the humanities, Mendoza (2015) notes the central role of voice in how emerging scholars see themselves. Defined as the particular analytic gaze one develops through the craft of scholarship, scholarly voice is developed by deeply understanding particular content within a discipline and having a specific scholarly perspective on that content. Honed by engaging in the scholarly process and critical inquiry, scholarly voice is the mechanism by which the researcher communicates to the larger disciplinary community and the world.

Scholarly voice is an individual's identity and positionality within the discipline. It evolves and develops though the recursive process of academic apprenticeship. Mentored undergraduate research is a process of modeling, doing, and discussing. Through this process, students begin to learn more about themselves and who they want to be as scholars. Self-discovery is an impetus for the formation and refinement of their scholarly identities. Mendoza (2015) also notes that faculty mentors perceive their role in facilitating the development of a student's scholarly voice as absolutely critical, since faculty view themselves as proxies for their disciplines. The development of scholarly voice can be perceived as an intellectual exercise, or more specifically as an extension of a scholarly persona or perspective. However, these perspectives are intimately connected with other identities. McNaryZak and Peters $(2011,17)$ state that "the significance of contextual influences upon a student means that one's location within the broader world impacts the questions one raises, the approaches one uses, what one sees as a meaningful research agenda, and the goals and means through which one conducts and evaluates research." Like 
an academic discipline, a minoritized identity serves as context, albeit a much more personal one.

\section{Balancing and Integrating the Student's Voice and the Field's Voice}

Underrepresented students engage in their education from a place of questioning. These students experience the educational system differently than majority students. Rendón (2009) notes that higher education privileges knowledge acquisition and mastery over social, personal, and spiritual development. Students regularly engage in curriculum that does not always recognize or celebrate their cultural identity and pedagogies that do not welcome their perspectives. Students are rarely asked to reflect on the meaning and purpose of their learning; rather, they are immersed in a culture of performance and assessment. Reflecting on her collegiate experience, Rendón (3) states, "I had been taught to be silent. The teacher was the expert. Instead I sat quietly; maybe I was the one who was wrong." This deep awareness of the level of personal knowledge may lead minoritized students to question whether they belong in an academic environment (Strayhorn 2012). Operating from a position of criticality is necessary as a mechanism of protection and survival. Students become strategic in their learning, consuming what is needed and discarding what is not. Within the collegiate context, this critical voice is not always recognized or legitimated.

As members of the academy, faculty members need to be aware that power structures influence the development of a student's scholarly voice. Minoritized students are negotiating academic spaces that were not designed with their learning at the center (Willinsky 1998). Students may want to engage in the classroom, but the simple act of questioning is perceived differently based on who is asking the question. A black man asking a question is responded to differently than a majority student (Harper and Quaye 2009). The development of voice for minoritized students is loaded and complex. It encompasses more than the juxtaposition of intense academic rigor and original scholarship (Palmer et al. 2015). It requires a willingness to be authentic in spaces where the minoritized student may not feel a sense of belonging. The role of faculty mentors in drawing out and nurturing this voice is essential to student success and UREs.

\section{Enhancing the Role and Meaning of Culture in Scholarly Voice}

It is critical that faculty realize and validate the life experiences of their students in order to develop a culturally relevant pedagogy and a culturally democratic academic environment. For the faculty member to evolve into a critical teacher and mentor, relevance must be gleaned from students' lives and perceptions and incorporated into the research experience, making both the experience and the subject under study more meaningful. Ladson-Billings
(2009) states that teachers and faculty members must ask their students pertinent questions about their experiences and perceptions, their shared research field, and their lived experiences. This deepens the faculty member's understanding of the student's worldview, which in turn enhances and informs the teaching and learning exchange. Ladson-Billings states that this culturally relevant approach creates a cultural democratic environment. Drawing cultural meaning from the student helps the faculty member understand the lens from which the student views the research and ultimately the discipline.

Faculty involved in UREs can utilize Freire's (2013) “culture circle," which allows each participant to add and share in the creation of knowledge. Cultural circles are egalitarian in design. They focus on a particular topic and provide a mechanism for the construction and deconstruction of knowledge through dialogue and problem solving. Using this model, research collaborations can result in the melding of an experienced faculty voice with the developing voice of the student as they describe their research. Coauthoring a scholarly paper or co-presenting at a conference are ways of creating a cultural circle. An activity involving a cultural circle can give students increased feelings of dignity, capability, and self-efficacy, which are often missing in the traditional education environment. Infusing cultural circles into pedagogy and research exchange allows students more autonomy to drive the process and develop their scholarly voices.

\section{Exploring Scholarly Personal Narratives and Positionality}

Brookfield $(2015,11)$ states "the starting point for dealing with teachers' problems should be teachers' own experiences." Thus, the authors decided upon the use of Scholarly Personal Narratives (SPNs) as an approach to explore the manner in which two faculty members engaged in UREs developed the scholarly voices of their underrepresented students. The use of SPNs squarely positioned the perceptions of the authors as the primary source of data. This approach used the development of narratives and the analysis and interpretation of experiences to delve into the practices and pedagogy of the faculty members. Purposeful self-study sampling was utilized for this narrative inquiry. This form of sampling is defined as the exploration of an individual's experience while engaging as the researcher (Patton 2014). The faculty members used their professional, pedagogical, and personal lenses to describe, derive meaning, and authenticate their lived experiences as URE faculty members for minoritized and underrepresented students.

The background of individuals is significant in shaping their realities, perceptions, and lenses (Bourke 2014). Therefore, acknowledging positionality is crucial when researching specific communities (Muhammad et al. 
2015). Both authors were involved in UREs as faculty members or administrators for numerous years, are ethnic minorities (black male and Latina female), and participated in UREs as undergraduate students. Their lenses are influenced by these lived experiences. This allows for unique, critical, and intimate comprehension of the importance of the scholarly voice for minoritized students and the URE experience. The considerations, results, and discussion below are a direct result of the authors' narratives and discussion.

\section{Developing the Student Voice through UREs}

In reflecting on their experiences as faculty, program administrators, and scholars, the authors posed considerations and questions that would invite minoritized perspectives into the conversation. In addition, the authors discussed elements of programmatic design that intentionally create space and experiences that promote a reflective scholarly journey for minoritized students.

Faculty and administrators engaged in undergraduate research and inquiry are uniquely positioned to support minoritized students as they begin their journey as scholars. Faculty mentors provide a foray into disciplinary culture and tradition for minoritized students. They guide, challenge, and encourage student learning and development. Similarly, undergraduate research program directors (URPDs) have the ability to create environments in which students are invited to engage authentically in scholarship while also providing faculty with additional support and training on best practices for mentoring diverse populations. Specifically, the authors identified two areas of consideration and focus: engagement in uncomfortable conversations, and an awareness of and active practice in ethnorelativism.

\section{Establishing UREs as Platforms for Difficult Dialogues}

A critical part of engaging in work that supports minoritized students is intentionally creating pathways and structures that are designed for their success. This process requires an awareness of professional limitations, a willingness to learn and operationalize theories, and an openness to adapting those theories into practices that support a specific student population as well as the campus climate. URPDs need to be deliberate and intentional. Without deliberately stepping into the space of constructing UREs that are overtly supportive of minoritized students, there is the risk that the benefits of student engagement will be perceived as magical, rather than a result of deliberately constructed learning environments.

For URPDs, the first step in creating UREs that embrace and support minoritized students is looking at their own professional training. Working at institutions that embrace liberal education and lifelong learning, they are adept at having conversations about pursuing rigor as a means to seek truth and practicing "humility, tolerance, and selfcriticism" (Cronon 1998, 77), but, as professionals, they need to engage these skills at the core of their work. This means creating space where they can acknowledge the oppressive structure of higher education for minoritized students and the potential nature of their disciplines to alienate. It requires a willingness to see the limitations of their canon, techniques of teaching and advising, and traditional programmatic design. Second, URPDs need to provide faculty with the support to engage in this work as well. Phelps-Ward and DeAngelo (2016) emphasize the need for faculty to recognize, understand, and examine issues of race and racial identity. This is an uncomfortable space for mentors, but providing a framework for learning and engaging in conversations about race, especially in cross-racial mentoring relationships, is paramount. URPDs are uniquely positioned to provide this support. By partnering with teaching and learning centers or offices of diversity and equity, UR programs can create space for faculty to learn and engage in "the work of becoming aware, examining, and engaging in dialogue about the differences in mentor/mentee's world view" (112). PhelpsWard and DeAngelo state that this process is critical for cross-racial mentoring relationships. In the current educational context, where the polarizing nature of views stifles conversation, URPDs need to give space to marginalized voices. This is not a task to be relegated to institutional offices of diversity, as many share in this work. The structure and content of mentor training offers examples of how URPDs can provide programmatic support for faculty engaged in cross-racial mentoring. In addition to providing general training about mentorship, URPDs should offer additional training and resources to faculty that examine research and evidence-based practices on how best to support minoritized populations. Pairing these materials with supportive mentoring colleagues allows for cultural humility and tacit action. This provides faculty with, on one hand, encouragement to engage in self-reflection, cultural self-exploration, and self-critiquing and, on the other, support and training mechanisms to engage in ongoing ethnorelative activity.

\section{Enacting Ethnorelativism as a Daily Practice}

For faculty members to engage in difficult conversations with students whose ethnic background, gender, socioeconomic status, and/or sexual orientation may be different from theirs, they must possess a secure sense of self. This sense of self allows faculty to engage in an exchange with students about their perceptions, experiences, and viewpoints. Bennett (1993) notes that individuals must possess a sound grasp of their own worldview before sufficiently engaging with the worldview of another. Thus, the mentor should engage in an intentional reflective process that includes listening to his or her own scholarly voice. A foray into this reflective process may include journal writing 
about personal perceptions and beliefs in relation to cultural paradigms. Engaging in this practice while writing about a personal understanding of other cultural paradigms can help bring meaning to social dynamics, perceived and real inequities, and the role of power in academia. Some faculty may find comfort in engaging in discussion with trusted colleagues about such topics. Regardless of the approach, the reflective process is critical. It can improve the faculty member's overall cultural understanding, enhance the ability to hear more clearly what the student is expressing, and aid in the promotion and development of the student's scholarly voice by supporting and infusing the student's cultural nuances and worldview. In reflecting on supporting faculty development, one author noted that colleagues rely on the comfort of research and statistics in supporting minoritized students and look past the individual stories and experiences of their mentees. Good practice should engage both an understanding of the aggregate experiences as well as an understanding of the importance of personal narratives. Ongoing exercises in ethnorelativism can ultimately assist the faculty mentor to become more aware of a student's cultural narrative and increase the likelihood of a positive and meaningful mentoring experience. This enhanced interaction fosters confidence and validity and helps students construct their own scholarly footpath. Faculty members must be keenly aware that a student's scholarly voice becomes associated with the faculty mentor's scholarly voice and that the student must also develop a voice that is genuine and independent of the mentor's voice.

\section{Engaging Faculty in Difficult Dialogues}

Faculty who are engaged in UREs may not realize that they are more than likely the faculty members to which their students are most connected. These students spend an inordinate amount of time with their URE faculty mentors as opposed to their instructors. These prolonged periods of time may result in the students developing trust in their faculty mentors. For minoritized students, finding a faculty member they can trust may be difficult and sometimes elusive. Bryk and Schneider (2002) state that trust is a crucial component in the educational process and is the major conduit of social capital. Therefore, it is within these relationships that faculty must engage in difficult conversations with their student mentees. These conversations may include discussion of students' experiences and issues of marginalization, experiences of being the only minoritized student in classes, isolation, uncomfortable situations on campus, and other student-specific topics. These exchanges provide opportunities for students to express themselves about their entire educational experiences. They also provide a safe platform for students to develop their own voices, since they are expressing genuine feelings and perspectives within the confines of a scholastic environment. Faculty must actively prepare themselves for these exchanges; initiate the conversations; and provide validation, support, and caring critical feedback to students. These conversations may occur throughout the mentoring process or at specific moments when a student may need the support of the faculty mentor. An example is a student's first scholarly conference. The culture of disciplinary associations and academic meetings can be disorienting for any undergraduate student. An underrepresented student may feel a heightened sense of discomfort for a variety of reasons. The association may be quite homogeneous and not have many people of color in attendance. There may be hidden costs that a poor student cannot afford. The student may experience microaggressions during the conference that are normalized or go unobserved by others. The practice of cultural relativism creates a more holistic view of the world. Having an expanded, socially critical, compassionate, and nonintrusive paradigm allows faculty to be more open, culturally comprehending, and useful to their students. It is critical for minoritized students to have a space in which their status as underrepresented is understood, valued, and honored. Faculty can create and nurture that space.

\section{Realizing Fear, Embracing Unorthodoxy, and Hearing Voice}

Brookfield (2015) describes the educational process, especially for teachers, as a messy and uneasy one. The same is true for URE faculty mentors who have minoritized students as mentees. This situation is one full of promise and has the potential to be extremely rewarding for both mentors and students. However, for faculty members, the exchange with students who possess fundamentally different identities may represent challenges that instill fear and doubt. It requires a distinct set of skills that may not be present at the beginning of the mentoring relationship. This lack of competency can create fear and anxiety. It is at this juncture that faculty mentors must delve into their core educational philosophy and realize that their role is to engage and provide students with an experience in which research skills, status as learners, and scholarly voice are nurtured. This nurturing requires potentially unorthodox approaches, a willingness to engage in difficult dialogues and explore personal culture, and an openness to listening and understanding a differing perspective. Hearing and encouraging the voices of minoritized populations requires intentionality and humility. The authors challenge faculty and administrators to consider additional aspects of criticality and determine how they may be infused into their programs to enable short-term and long-term outcomes. The challenge for administrators of UREs is to provide the resources, support, and purposeful platforms for their faculty mentors. The challenge for faculty is to embrace cultural humility and become flexible in their approach to students.

In addition, the authors emphasize that the responsibility of faculty and administrators of UREs is to guide students 
in academic development, to encourage their socialization within the field, and to help them become contributing members of society. Recognizing that the purpose of UREs is multilayered, there are a number of steps that can prepare faculty and URPDs to support minoritized students. First, faculty should actively seek and consult with diversity professionals at their institution to better understand the importance of diversity and equity, the cultural dynamic of the campus, and nodes of support for faculty. This garners a perspective of the campus climate beyond individual cultural lenses. Second, faculty must actively pursue lifelong learning through self-reflection and cultural awareness and learn how dominant-subdominant social dynamics, societal inequities, and social privilege impact their world and higher education. Understanding and struggling with personal cultural proclivity is essential to becoming an individual who can constructively interact with someone of a differing culture or ethnicity. Intentional focus on these areas deepens the ability to consciously listen, refrain from superimposing a personal paradigm onto another's lived experience, and respect the equal validity of experiences. By hearing, comprehending, and appreciating the voices of others, mentors and others ultimately can validate and nurture the voices of students. This validation and support prepare students to actively engage in their future careers from a place of confidence, integration, and resiliency.

\section{References}

Abdul-Alim, Jamaal. 2014. "Colleges Urged to Take Advising of Underrepresented Students to Deeper Level." Diverse Issues in Higher Education, September 8, 2014. http://diverseeducation. com/article/66772

Allen, Taryn O. 2016. "Validation in the Minority: The Experiences of Latino Students Enrolled in an HBCU." Journal of Higher Education 87: 461-487. doi: 10.1080/00221546.2016.11777410

Bennett, Milton J. 1993. "Towards Ethnorelativism: A Developmental Model of Intercultural Sensitivity." In Education for the Intercultural Experience, 3rd ed., ed. R. M. Paige, 21-71. Yarmouth, ME: Intercultural Press.

Bourke, Brian. 2014. "Positionality: Reflecting on the Research Process." Qualitative Report 19: 1-9.

Brookfield, Stephen. 2000. "Contesting Criticality: Epistemological and Practical Contradictions in Critical Reflection," Adult Education Research Conference. http://newprairiepress. org/aerc/2000/papers/11

Brookfield, Stephen. 2015. The Skillful Teacher: On Technique, Trust, and Responsiveness in the Classroom, 3rd ed. San Francisco: Jossey-Bass.

Bryk, Anthony, and Barbara Schneider. 2002. Trust in Schools: A Core Resource for Improvement. New York: Russell Sage Foundation.

Castillo, Yuleinys, and Antonio Estudillo. 2015. "Undergraduate Research: An Essential Piece for Underrepresented Students' College Success." Perspectives on Undergraduate Research and Mentoring 4.1. http://blogs.elon.edu/purm/2015/11/16/ undergraduate-research-an-essential-piece-for-underrepresentedstudents-college-success

Cronon, William. 1998. “'Only Connect': The Goals of a Liberal Education.” American Scholar 67(4): 73-80.

DeAngelo, Linda, Jessica Mason, and Dana Winters. 2016. "Faculty Engagement in Mentoring Undergraduate Students: How Institutional Environments Regulate and Promote ExtraRole Behavior." Innovative Higher Education 41: 317-332. doi: 10.1007/s10755-015-9350-7

Eagan, M. Kevin, Sylvia Hurtado, Mitchell J. Chang, Gina A. Garcia, Felisha A. Herrera, and Juan C. Garibay. 2013. "Making a Difference in Science Education: The Impact of Undergraduate Research Programs." American Educational Research Journal 50: 683-713. doi: 10.3102/0002831213482038

Freire, Paulo. 2013. Education for a Critical Consciousness. New York: Bloomsbury Academic.

Gittens, Cheryl B. 2014. "The McNair Program as a Socializing Influence on Doctoral Degree Attainment." Peabody Journal of Education 89: 368-379. doi: 10.1080/0161956x.2014.913450

Harper, Shaun R., and Stephen J. Quaye. 2009. Student Engagement in Higher Education: Theoretical Perspectives and Practical Approaches for Diverse Populations. New York: Routledge.

Hunter, Anne-Barrie, Sandra L. Laursen, and Elaine Seymour. 2007. "Becoming a Scientist: The Role of Undergraduate Research in Students' Cognitive, Personal, and Professional Development." Science Education 91: 36-74. doi: 10.1002/ sce. 20173

Hunter, Anne-Barrie, Timothy J. Weston, Sandra L. Laursen, and Heather Thiry. 2009. "URSSA: Evaluating Student Gains from Undergraduate Research in the Sciences." CUR Quarterly 29(3): 15-19.

Ladson-Billings, Gloria. 2009. The Dreamkeepers: Successful Teachers of African American Children, 2nd ed. San Francisco: Jossey-Bass.

Lopatto, David. 2007. "Undergraduate Research Experiences Support Science Career Decisions and Active Learning." CBE-Life Sciences Education 6: 297-306. doi: 10.1187/ cbe.07-06-0039

McNary-Zak, Bernadette, and Rebecca Todd Peters. 2011. Teaching Undergraduate Research in Religious Studies. Oxford: Oxford University Press.

Mendoza, Susan. 2015. "Redefining Significance: Experience of Humanities Faculty Engaged in Undergraduate Research.” PhD diss., Western Michigan University.

Muhammad, Michael, Nina Wallerstein, Andrew L. Sussman, Magdalena Avila, Lorenda Belone, and Bonnie Duran. 2015. "Reflections on Researcher Identity and Power: The Impact of Positionality on Community-Based Participatory Research (CBPR) Processes and Outcomes." Critical Sociology 41: 10451063. doi: $10.1177 / 0896920513516025$

Museus, Samuel D., Susan. A. Lambe Sariñana, and Tasha Kawamata Ryan. 2015. "A Qualitative Examination of Multiracial 
Students' Coping Responses to Experiences with Prejudice and Discrimination in College." Journal of College Student Development 56: 331-348. doi: 10.1353/csd.2015.0041

Palmer, Ruth J., Andrea N. Hunt, Michael Neal, and Brad Wuetherick. 2015. "Mentoring, Undergraduate Research, and Identity Development: A Conceptual Review and Research Agenda." Mentoring \& Tutoring: Partnership in Learning 23: 411-426. doi: 10.1080/13611267.2015.1126165

Pascarella, Ernest T., and Patrick T. Terenzini. 2005. How College Affects Students: A Third Decade of Research, 2nd ed. San Francisco: Jossey-Bass.

Patton, Michael Q. 2014. Qualitative Research \& Evaluation Methods, 4th ed. Thousand Oaks, CA: SAGE Publications.

Phelps-Ward, Robin, and Linda DeAngelo. 2016. "Feeding the Pipeline toward the Doctorate: Examining the Formal Mentoring Experiences of Black Undergraduate Students." Western Journal of Black Studies 40: 111-125.

Rendón, Laura I. 2009. Sentipensante (Sensing/Thinking) Pedagogy: Educating for Wholeness, Social Justice and Liberation. Sterling, VA: Stylus.

Russell, Susan H., Mary P. Hancock, and James McCullough. 2007. "The Pipeline: Benefits of Undergraduate Research Experiences." Science 316: 548-549. doi:10.1126/science.1140384

Seltzer, Richard, and Nicole E. Johnson. 2009. Experiencing Racism: Exploring Discrimination through the Eyes of College Students. Lanham, MD: Lexington Books.

Strayhorn, Terrell L. 2012. College Students' Sense of Belonging: A Key to Educational Success for All Students. New York: Routledge.

Strayhorn, Terrell L. 2014. "Beyond the Model Minority Myth: Interrogating the Lived Experiences of Korean American Gay Men in College." Journal of College Student Development 55: 586-594. doi:10.1353/csd.2014.0059
Tinto, Vincent. 1993. Leaving College: Rethinking the Causes and Cures of Student Attrition, 2nd ed. Chicago: University of Chicago Press.

Willinsky, John. 1998. Learning to Divide the World: Education at Empire's End. Minneapolis: University of Minnesota Press.

\section{Susan G. Mendoza}

Grand Valley State University, mendozsu@gvsu.edu

Susan Mendoza is the founding director of the Office of Undergraduate Research and Scholarship at Grand Valley State University (GVSU). Her area of specialty as a scholar practitioner is the intersection of disciplinary epistemology, high-impact interventions, and student agency. She is a former State of Michigan's Martin Luther King/ César Chavez/Rosa Parks Future Faculty Fellow. She earned her PhD in higher education administration from Western Michigan University; a master of arts in student affairs administration from Michigan State University; and a bachelor of arts in anthropology and a bachelor of arts in integrative social science and political science, both from Michigan State University.

Dave A. Louis is an associate professor of higher education at Texas Tech University. His primary research is in cross-cultural mentoring in the American academy, including the recent publication "Cross-Gender Mentoring from a Caribbean Perspective," in Caroline Sotello Viernes Turner's Modeling Mentoring across Race/Ethnicity and Gender: Practices to Cultivate the Next Generation of Diverse Faculty (2014). He served as the associate director of undergraduate research for the honors program at Texas A\&M University and is a former McNair Scholar and Oprah Winfrey Scholar at Morehouse College. He earned his PhD at Texas A\&M University, master of education degree at Harvard University, and bachelor of arts degree in psychology at Morehouse College. 